\title{
Mycolic Acid Patterns of Representative Strains of Mycobacterium fortuitum, 'Mycobacterium peregrinum' and Mycobacterium smegmatis
}

\author{
By D. E. MINNIKIN, ${ }^{1 *}$ S. M. MINNIKIN, ${ }^{1}$ I. G. HUTCHINSON, ${ }^{1}$ \\ M. GOODFELLOW ${ }^{2}$ AND J. M. GRANGE ${ }^{3}$ \\ ${ }^{1}$ Department of Organic Chemistry, The University, Newcastle upon Tyne NE1 7RU, UK \\ ${ }^{2}$ Department of Microbiology, The University, Newcastle upon Tyne NEI 7RU, UK \\ ${ }^{3}$ Cardiothoracic Institute, Brompton Hospital, Fulham Road, London SW3 6HP, UK
}

(Received 8 September 1983)

\begin{abstract}
Representative strains of Mycobacterium fortuitum, 'Mycobacterium peregrinum' and Mycobacterium smegmatis were degraded by acid methanolysis and patterns of long-chain compounds were determined by two-dimensional thin-layer chromatography. The same general pattern of mycolic acid methyl esters was found in all 39 strains examined, the major components being socalled $\alpha$-mycolates and characteristic pairs of polar mycolates. Analysis of alkaline methanolysates of selected strains confirmed that these polar mycolates were derived from epoxymycolic acids, as found previously.
\end{abstract}

\section{INTRODUCTION}

Mycolic acids are characteristic high molecular weight 3-hydroxy 2-alkyl branched fatty acids whose discontinuous distribution is of value in both the classification and identification of mycobacteria (Minnikin \& Goodfellow, 1980). Mycobacterial mycolic acids contain between 60 and 90 carbons and different structural types include so-called $\alpha$-mycolates and acids having oxygen functions ( $>\mathrm{C}=\mathrm{O},>\mathrm{CH}-\mathrm{OCH}_{3},-\mathrm{COOH}$ ) in addition to the 3-hydroxy acid unit (Minnikin, 1982). The carbon skeletons of both oxygenated and $\alpha$-mycolic acids may contain either double bonds or cyclopropane rings and methyl branches may be present. By use of thinlayer chromatography (TLC) of methanolysates of whole organisms (Minnikin et al., 1980) it has been shown that four characteristic patterns of mycobacterial mycolic acid methyl esters are commonly encountered. The mycolic acids of Mycobacterium tuberculosis, consisting of $\alpha$ mycolates, ketomycolates and methoxymycolates, are an example of the first pattern and the second, shown by Mycobacterium avium for example, has $\omega$-carboxymycolates and 2-eicosanol and homologues, together with $\alpha$-mycolates and ketomycolates (Minnikin et al., 1980; Minnikin \& Goodfellow, 1980; Minnikin, 1982). A third pattern, found only in Mycobacterium chelonei and close relatives, contains only $\alpha$ - and $\alpha^{\prime}$-mycolates (Minnikin, 1982; Minnikin et al., 1982a). The fourth main pattern discovered in Mycobacterium fortuitum and Mycobacterium smegmatis (Minnikin et al., 1980) showed the presence of characteristic polar mycolates co-occurring with $\alpha$-mycolates and this pattern was found to be characteristic of representatives of Mycobacterium farcinogenes and Mycobacterium senegalense (Ridell et al., 1982). It has been shown that these characteristic polar mycolates are derived from epoxymycolates in these taxa (Daffé et al., 1981; Minnikin et al., 1982 b). In the present paper mycolic acid patterns of representative strains of $M$. fortuitum, $M$. smegmatis and ' $M$. peregrinum' have been investigated to determine their taxonomic value and to assess the distribution of epoxymycolates and their acid methanolysis products.

\section{METHODS}

Strains and cultication. Cultures (Table 1) were maintained on glucose yeast agar (Gordon \& Mihm, 1962) at room temperature and cultivated in shake flasks of modified Sauton's medium (Mordarska et al., 1972) for 5 to $7 \mathrm{~d}$ 
Table 1. Designation and sources of test strains

Strain no.

Designation and source

M32

M61, M62

M172

M173

M174

M175

M195

M199

M204

M226

M227

M229

M230

M232

M233

M234

M235

M236

M237

M238

M6

M418-M423

M424

M425, M426

M427

'M59

M101

M215

M216

M217

M218

M219
Mycobacterium fortuitum, Institute d'Hygiene, Lausanne, Switzerland, LA 1263

M. fortuitum, I. Baess, Statens Seruminstitut, Copenhagen, Denmark, F656, F141

$M$. fortuitum, J. M. Grange, 108; J. Marks, 16575 PC; sputum

$M$. fortuitum, J. M. Grange, 487; Gatti, 750; abscess

$M$. fortuitum, J. M. Grange, 5; NCTC 2006; terrapin

M. fortuitum, J. M. Grange, 630; ATCC 23021; human

M. fortuitum, J. M. Grange, 650; ATCC 23041; abscess

$M$. fortuitum, J. M. Grange, R44; Ugandan mud

$M$. fortuitum, NCTC 10394; J. C. Cruz 1; cold abscess. Type strain

$M$. fortuitum, J. M. Grange, 33; abscess

M. fortuitum, J. M. Grange, 109; J. Marks, 18519 PC; sputum

M. fortuitum, J. M. Grange, 113; J. Marks, 37379 PC; sputum

$M$. fortuitum, J. M. Grange, 443; sputum

$M$. fortuitum, J. M. Grange, 557; clinical isolate

$M$. fortuitum, J. M. Grange, 677; abscess

$M$. fortuitum, J. M. Grange, 678; zoo aquarium

M. fortuitum, J. M. Grange, 802; gastric washings

$M$. fortuitum, J. M. Grange, 806; frog

M. fortuitum, J. M. Grange, 81; NCTC 2891; frog

M. fortuitum, J. M. Grange, 491 ; urine

'Mycobacterium peregrimum', NCTC 10264; bronchial aspirate of child. Type strain.

'M. peregrinum', P. A. Jenkins, Mycobacterium Reference Unit, University Hospital of Wales, Cardiff, Wales, UK, 7678, 7680, 14654, 14657, 14894, 14895; sputum

'M. peregrinum', P. A. Jenkins, 16788; peritoneal fluid

'M. peregrinum', P. A. Jenkins, 17564 ; 14462; urine

'M. peregrinum', P. A. Jenkins, 19774; sputum

Myobacterium smegmatis, I. Baess, F87

M. smegmatis, ATCC 11468

M. smegmatis, J. M. Grange, 1; NCTC 333

M. smegmatis, J. M. Grange, 2; NCTC 8159. Type strain

M. smegmatis, J. M. Grange, 77; NCTC 10265

$M$. smegmatis, J. M. Grange, 138 ; milk

M. smegmatis, J. M. Grange, 607; ATCC 607

- Abbreviations: NCTC, National Collection of Type Cultures, Colindale Avenue, London, UK; ATCC, American Type Culture Collection, Rockville, Maryland, USA.

at $30^{\circ} \mathrm{C}$. After checking for purity at maximum growth, organisms were killed with formaldehyde $(1 \%, \mathrm{v} / \mathrm{v})$, harvested by centrifugation, washed with distilled water and freeze-dried. Bacterial names that do not appear in the Approved Lists of Bacterial Names (Skerman et al., 1980), or subsequent validation lists published in the International Journal of Systematic Bacteriology, are written in quotation marks.

Mycolic acid analysis. Acid methanolysates of dry bacteria $(50 \mathrm{mg})$ were prepared as described previously (Minnikin et al., 1980). Alkaline methanolysates (West, 1975; Minnikin et al., 1982b) of selected strains were made by treating organisms $(50 \mathrm{mg})$ at $37{ }^{\circ} \mathrm{C}$ overnight with $20 \%$ methanolic tetramethylammonium hydroxide (Aldrich) $(0.5 \mathrm{ml})$, toluene $(0.5 \mathrm{ml})$ and methanol $(1.0 \mathrm{ml})$. The supernatant was removed after centrifugation and the organisms washed with methanol/toluene $(2: 1, \mathrm{v} / \mathrm{v})(1 \mathrm{ml})$. Dimethylformamide $(3 \mathrm{ml})$ was added to the combined supernatants and approximately $3 \mathrm{ml}$ of methanol and toluene were removed by evaporation under a stream of nitrogen. After adding a $10 \%$ solution of iodomethane in dimethylformamide $(1 \mathrm{ml})$ and mixing for $1 \mathrm{~h}$, the mixture was extracted with petroleum ether (b.p. $\left.60-80^{\circ} \mathrm{C}\right)(4 \mathrm{ml}$ followed by $2 \times 2 \mathrm{ml})$. The extracts were evaporated to about $1 \mathrm{ml}$ in volume and the residue was then extracted with more petroleum ether $(1 \mathrm{ml}$ followed by $2 \times 0.5 \mathrm{ml}$ ) to remove residual dimethylformamide. The final extract was evaporated to dryness under a stream of nitrogen.

Analytical two-dimensional TLC (Minnikin et al., 1980) was performed at first on $20 \times 20 \mathrm{~cm}$ layers $(0.5 \mathrm{~mm})$ of Merck 7739 silica gel $60 \mathrm{HF}_{254}$, but subsequently $10 \times 10 \mathrm{~cm}$ pieces of Merck 5554 silica gel $60 \mathrm{~F}_{254}$ aluminium sheets were used. A triple development with petroleum ether (b.p. $\left.60-80^{\circ} \mathrm{C}\right) /$ acetone $(95: 5, \mathrm{v} / \mathrm{v})$ in the first direction was followed in the second direction by a single development with toluene/acetone $(97: 3, \mathrm{v} / \mathrm{v})$. The presence of separated components was revealed by spraying with $10 \%$ ethanolic molybdophosphoric acid followed by charring at $150^{\circ} \mathrm{C}$ for $15 \mathrm{~min}$. 


\section{RESULTS AND DISCUSSION}

Samples of all the test strains (Table 1) were subjected to acid methanolysis and selected organisms to alkaline methanolysis. The results of TLC analysis of both acid and alkaline methanolysates of representatives of $M$. fortuitum, $M$. smegmatis and ' $M$. peregrinum' are shown in Fig. 1. In all three cases acid methanolysates contained the characteristic pairs of polar mycolates (Fig. 1, I, J, N, O) found previously in strains of the former two species (Minnikin et al., 1980; Minnikin, 1982). These components were absent in the alkaline methanolysates (Fig. 1) being replaced by a component ' $M$ ' shown in previous studies to be an epoxymycolic acid methyl ester (Minnikin et al., 1982b). All three representative strains have components corresponding to $\alpha$-mycolates and non-hydroxylated fatty acid methyl esters in both types of methanolysates (Fig. 1). The strain of M. smegmatis studied has substantial amounts of an $\alpha^{\prime}$ mycolate and the ' $M$. peregrinum' representative contained a small amount of an uncharacterized acid-stable component labelled ' $\mathrm{K}$ ' (Fig. 1), whose presence in methanolysates of $\boldsymbol{M}$. fortuitum (Minnikin et al., 1980), M. farcinogenes and $M$. senegalense (Minnikin et al., 1982b; Ridell et al., 1982) has been previously noted.

TLC analysis of acid methanolysates of the remaining test strains (Table 1) showed that the same general pattern (Fig. 1), containing the characteristic components $I, J, N$, and $O$, was present in all cases. Copies of these patterns have been deposited with the British Library Lending Division, Boston Spa, Yorkshire LS23 7BQ, UK, as Supplementary Publication no. SUP 28015 (6 pp.). (Copies may be obtained from the BLLD on demand; wherever possible, requests should be accompanied by prepaid coupons, held by many university and technical libraries and by the British Council.)

In addition to the components $\mathrm{F}, \mathrm{A}, \mathrm{I}, \mathrm{J}, \mathrm{N}$ and $\mathrm{O}$ found in all acid methanolysates some of the minor components were discontinuously distributed. The spot labelled ' $L$ ' in the acid methanolysate of ' $M$. peregrinum' M6 (Fig. 1) was detected as a minor component in $M$. fortuitum M32, M61, M172, M174, M175, M230, M232, M233, M234 and M238 but not in any of the other strains of ' $M$. peregrinum'. The structure of component ' $L$ ' is unknown, but, as it is an artefact formed in an erratic manner by acid methanolysis of epoxymycolates (Minnikin et al., $1982 b$ ), it is not a reliable chemotaxonomic character. Component ' $\mathrm{K}$ ' is, however, consistently present in both acid and alkaline methanolysates, as shown for ' $M$. peregrinum' M6 in Fig. 1, and it may have possible chemotaxonomic value. All strains of $M$. fortuitum and ' $M$. peregrinum' contained small amounts of $\mathrm{K}$ in their methanolysates with the exceptions of $M$. fortuitum M199, M204 (Fig. 1), M227, M235 and 'M. peregrinum' M422, M423, M425; this component was present only in one representative, M216, the type strain of $M$. smegmatis.

The other potentially valuable components in methanolysates of these mycobacteria are the lower molecular weight $\alpha^{\prime}$-mycolates represented by the spot $\mathrm{A}^{\prime}$ in the methanolysates of $M$. smegmatis M59 (Fig. 1). When large amounts of $\alpha^{\prime}$-mycolates are present in methanolysates of, for example, $M$. chelonei (Minnikin et al., 1982a) their presence can be readily seen on TLC but small amounts are less easily distinguished from the $\alpha$-mycolates (spot A, Fig. 1). All representatives of ' $M$. peregrinum' appeared to lack $\alpha$ '-mycolates but they were present in all representatives of $M$. smegmatis excepting M216. Mycobacterium fortuitum M61, M172, M195, M199, M226, M227, M229, M230, M235 and M237 did not contain clearly recognizable amounts of $\alpha^{\prime}$-mycolates. The detection of small amounts of $\alpha^{\prime}$-mycolates may require the use of quantitative chromatographic techniques such as high-performance liquid chromatography (Steck et al., 1978).

The related patterns shown by the methanolysates of the representative strains of $M$. fortuitum and $M$. smegmatis confirm and extend the results of an earlier study based upon single strains of the two species (Minnikin et al., 1980). Mycobacterium fortuitum and M. smegmatis form distinct and separate clusters in numerical phenetic surveys (Kubica et al., 1972; Tsukamura, 1981) and have little DNA in common in homology studies (Baess \& Weis-Benzon, 1978; Baess, 1982) but the lipid data raise the possibility that they might have a fairly close phylogenetic relationship. The mycolic acid data do not contradict the classification of ' $M$. peregrinum' (Bojalil et al., 1962) as a subjective synonym of $M$. fortuitum (Kubica et al., 1972; Grange \& Stanford, 1974; Pattyn et al., 1974; Tsukamura, 1981), although TLC analysis of mycobacterial mycolates does not 


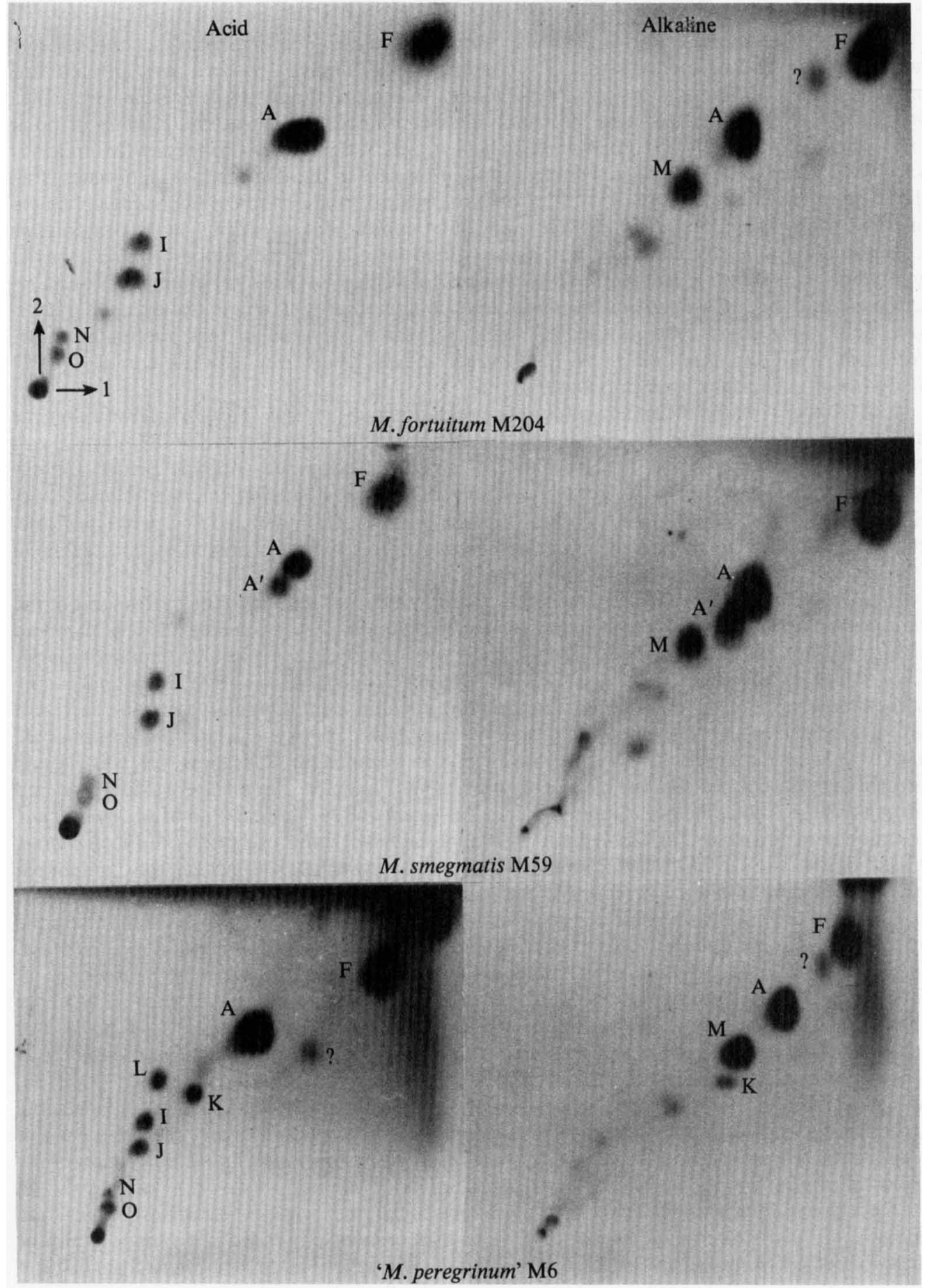

Fig. 1. Two-dimensional TLC of whole-organism acid and alkaline methanolysates of $M$. fortuitum M204, M. smegmatis M59 and ' $M$. peregrinum' M6. A triple development with petroleum ether (b.p. 60$\left.80^{\circ} \mathrm{C}\right) /$ acetone $(95: 5, \mathrm{v} / \mathrm{v})$ was used in the first direction followed by a single development with toluene/acetone $(97: 3, \mathrm{v} / \mathrm{v})$ in the second direction. Abbreviations: $\mathrm{F}$, non-hydroxylated fatty acid methyl esters; A, $\alpha$-mycolate; $A^{\prime}$, $\alpha^{\prime}$-mycolate; $\mathbf{K}$, unknown mycolate; $M$, epoxymycolate; I, J, L, N and $\mathrm{O}$, components derived from epoxymycolates by acid methanolysis. 
necessarily give data sufficiently sensitive for the circumscription of species (Minnikin \& Goodfellow, 1980; Ridell et al., 1982). 'Mycobacterium peregrinum' can, however, be distinguished from $M$. fortuitum using chemical and serological criteria (Jenkins et al., 1971) and it has been suggested that the taxon be revised as a separate species on the basis of results from DNA homology studies (Baess, 1982).

Two of us (M.G. and D. E. M.) are grateful for support from the Medical Research Council (G974/522/S) and the Science and Engineering Research Council (GRA88651). We are also indebted to Dr P. A. Jenkins for the gift of the 'M. peregrinum' strains.

\section{REFERENCES}

BAESS, I. (1982). Deoxyribonucleic acid relatedness among species of rapidly growing mycobacteria. Acta pathologica et microbiologica scandinavica Section $B$ 90, 371-375.

Baess, I. \& Weis Bentzon, M. (1978). Deoxyribonucleic acid hybridization between different species of mycobacteria. Acta pathologica et microbiologica scandinavica Section B 86, 71-76.

Bojalil, L. F., Cerbón, J. \& Trujillo, A. (1962). Adansonian classification of mycobacteria. Journal of General Microbiology 28, 333-346.

Daffé, M., Lanéelle, M. A., Puzo, G. \& Asselineau, C. (1981). Acide mycolique epoxydique: un nouveau type dacide mycolique. Tetrahedron Letters 22 , 4515-4516.

GORDON, R. E. \& MiHM, J. M. (1962). Identification of Nocardia caviae (Erikson) nov. comb. Annals of the New York Academy of Sciences 98, 628-636.

Grange, J. L. \& Stanford, J. L. (1974). Reevaluation of Mycobacterium fortuitum (synonym: Mycobacterium ranae). International Journal of Systematic Bacteriology 24, 320-329.

Jenkins, P. A., Marks, J. \& Schaefer, W. B. (1971). Lipid chromatography and seroagglutination in the classification of rapidly growing mycobacteria. American Review of Respiratory Disease 103, 179-187.

Kubica, G. P., Baess, I., Gordon, R. E., Jenkins, P. A., Kwapinski, J. B. G., McDurmont, C., Pattyn, S. R., Saito, H., Silcox, V., Stanford, J. L., Takeya, K. \& Tsukamura, M. (1972). A cooperative numerical analysis of rapidly growing mycobacteria. Journal of General Microbiology 73, $55-70$.

Minnikin, D. E. (1982). Lipids: complex lipids, their chemistry, biosynthesis and roles. In The Biology of the Mycobacteria, vol. 1, pp. 95-184. Edited by C. Ratledge \& J. L. Stanford. London: Academic Press.

MinNikin, D. E. \& Goodfellow, M. (1980). Lipid composition in the classification and identification of acid-fast bacteria. In Microbiological Classification and Identification, pp. 189-256. Edited by M. Goodfellow \& R. G. Board. London: Academic Press.

Minnikin, D. E., Hutchinson, I. G., Caldicott,
A. B. \& Goodfellow, M. (1980). Thin-layer chromatography of methanolysates of mycolic acidcontaining bacteria. Journal of Chromatography 188, 221-233.

Minnikin, D. E., Minnikin, S. M., Goodfellow, M. \& STANFORD, J. L. $(1982 a)$. The mycolic acids of Mycobacterium chelonei. Journal of General Microbiology 128, 817-822.

Minnikin, D. E., Minnikin, S. M. \& Goodfellow, M. $(1982 b)$. The oxygenated mycolic acids of Mycobacterium fortuitum, $M$. farcinogenes and $M$. senegalense. Biochimica et biophysica acta 712, 616620.

Mordarska, H., Mordarski, M. \& Goodfellow, M. (1972). Chemotaxonomic characters and classification of some nocardioform bacteria. Journal of General Microbiology 71, 77-86.

Pattyn, S. R., Magnusson, M., Stanford, J. L. \& Grange, J. M. (1974). A study of Mycobacterium fortuitum (ranae). Journal of Medical Microbiology 7, 67-76.

Ridell, M., Goodfellow, M., Minnikin, D. E., Minnikin, S. M. \& Hutchinson, I. G. (1982). Classification of Mycobacterium farcinogenes and Mycobacterium senegalense by immunodiffusion and thin-layer chromatography of long chain components. Journal of General Microbiology 128, 1299 1307.

Skerman, V. B. D., McGowan, V. \& Sneath, P. H. A. (1980). Approved lists of bacterial names. International Journal of Systematic Bacteriology 30, 225-420.

Steck, P. A., Schwartz, B. A., Rosendahl, M. S. \& Gray, G. R. (1978). Mycolic acids. A reinvestigation. Journal of Biological Chemistry 253, 5625-5629.

TsUKamURA, M. (1981). Numerical analysis of rapidly growing, non-chromogenic mycobacteria. including Mycobacterium agri (Tsukamura 1972) Tsukamura sp. nov., nom. rev. International Journal of Systematic Bacteriology 31, 247-258.

WEST, J. C. (1975). Rapid preparation of methyl esters from lipids, alkyd paint resins, polyester resins and ester plasticizers. Analytical Chemistry 47, 17081709. 